\title{
A COMPARATIVE ANALYSIS OF TILMICOSIN PRODUCTION VARIETIES APPLIED TO PIGS
}

\author{
Kaloyan Yankov, Miglena Kazakova \\ Faculty of Technics and Technologies, Trakia University, Yambol, \\ 38 Graf Ignatiev str., 8602, Yambol, Bulgaria \\ e-mail: kaloyan.yankov@trakia-uni.bg
}

\begin{abstract}
In the present work, a comparative analysis of two production forms of the antibiotic tilmicosin was performed after intravenous administration. The experiment was conducted on two groups of pigs, each of 10 animals, and the pharmacokinetic curves were received. A mathematical model of the curves is identified and on its basis, the dynamic parameters of the processes are calculated. A statistically significant difference $(p$-level $<0.05)$ was found in only two parameters - initial value concentration and time-correction parameter. A statistically significant difference only of one dynamic parameter is found - the power of the pharmacokinetic curve. The final conclusion is that the two forms of tilmicosin have the same effect on the experimental animals.
\end{abstract}

Keywords: pharmacokinetics, tilmicosin, identification, mathematical model, dynamic parameters.

\section{INTRODUCTION}

Tilmicosin is an antibiotic for use in veterinary medicine. In pigs, it is used for the treatment and prevention of bacterial respiratory diseases associated with Mycoplasma gallisepticum, Mycoplasma synoviae, Ornithobacterium rhinotracheale, Pasteurella multocida and others. drug-sensitive micro-organisms.

Tilmicosin is available from pharmaceutical manufacturers with different brand names. The identification of differences in the action of drugs containing the same active ingredient is a laborious and complex task. The statistical comparison of the pharmacokinetic curves is not always appropriate due to the small number of parameters that can be compared.

When the pharmacokinetic curve is presented with an algebraic equation, then the functional analysis can be used to compare and evaluate the action of the drug. Differences can thus be found or, on the contrary, the identity and indistinguishability of drugs are proven.

The purpose of this work is to determine whether there is a difference in the action of two tilmicosin forms. By introducing a mathematical model of the pharmacokinetic curves of the two forms and calculating additional parameters for their evaluation, a statistically significant difference will be sought for them.

\section{MATERIAL AND METHODS}

\subsection{Experimental animals}

In order to preserve the anonymity of the manufacturer and of the trade name of the product, each drug will bear the name of the group of animals to which "Drug1 (D1)" and "Drug2 (D2)" have been applied. The data for drugs D1 and D2 administered to 10 male and female healthy pigs, 9-10 weeks of age with a body weight of 9-14.5 kg. 


\section{IRTITE}

Ipplied Resseirlohes in Technics, Technologies and Eductition

Journal of the Faculty of Technics and Technologies, Trakia University https://sites.google.com/a/trakia-uni.bg/artte/

\subsection{Order of the experiment}

Blood samples were investigated after intravenous (iv) injection of tilmicosin at $0.25,0.5,1$, $1.5,2,3,4,6,8,12,24,48,72$ hours according to the procedure presented in [1,2]. Concentration was determined by HPLC with fluorescence detection. The experimental protocol of the study was approved by the Institutional Animal Care and in accordance with the national regulations, and European Directive of 22.09.2010 (210/63/EU) concerning the protection of animals used for scientific and experimental purposes.

\subsection{Data processing}

Statistical processing was performed with STATISTICA 13, Statsoft Inc. A p-level<0.05 was accepted as statistically significant. The Shapiro-Wilk test was used to verify normal distribution of data. For each data set, an arithmetic mean value, standard deviation SD, skewness and kurtosis are calculated. A statistically significant difference between the parameters of both drugs was sought with the Student-Fisher t-test. The identification of pharmacokinetic curves and the obtaining of the values of the dynamic processes is done with a program Korelia-Ident.

\subsection{Identification of pharmacokinetic curves}

The change in drug concentration in iv administration is characterized by a steep growth front and a decreasing downward branch. The increase in blood concentration may be presented as Dirac function, therefore it cannot be a characteristic of the action of the preparation or of the body's response. For that reason, the object of study will be the downstream branch of the process presenting the elimination phase. The concentration change curve is represented in Figure 1 and can be described by the exponential equation [6]:

$$
C(t)=\left(C_{0}-C_{\infty}\right) \cdot e^{-k \cdot t}+C_{\infty}
$$

where: $k$ is the rate of absorption of the drug;

$\mathrm{C}_{0}=\mathrm{C}(0)-$ initial concentration;

$\mathrm{C}_{\infty}=\mathrm{C}(\mathrm{t} \rightarrow \infty)-$ infinite asymptote.

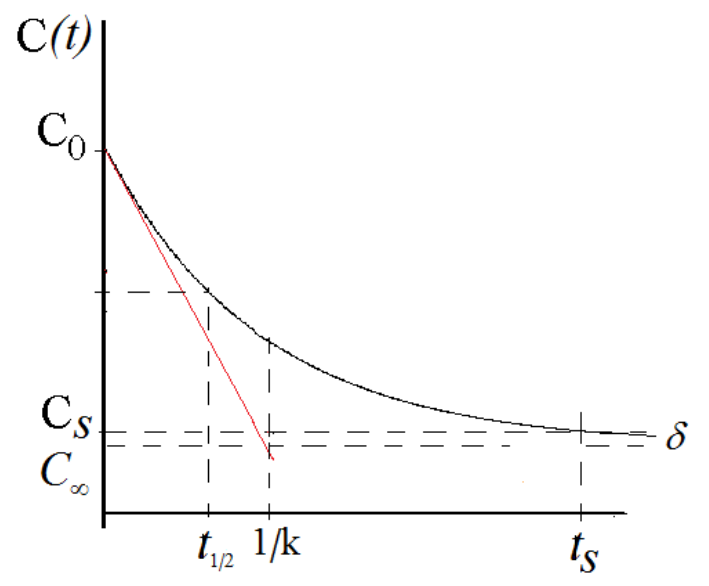

Figure 1. Pharmacokinetic curve of a drug and parameters of the process

IRTIIE Vol. 5, No. 4, 2017 ISSN 1314-8788 (print), ISSN 1314-8796 (online), doi: 10.15547/artte.2017.04.004 


\section{IRTIIE}

Ipplied Researrches in Technics, Technologies ind Bducition

Journal of the Faculty of Technics and Technologies, Trakia University https:///ites.google.com/a/trakia-uni.bg/artte/

\subsection{Dynamic parameters for estimation of kinetic curves}

The graph of a process allows direct measuring a number of parameters. However, the presence of a mathematical model makes it possible to calculate features inaccessible from the graphic. Using a mathematical model, it is possible to apply control theory to analyze, evaluate, and compare processes [4,5].

Inverse function. The pharmacokinetic curve is a monotone, continuous function that ensures the existence of a inverse function. It gives the time to reach the desired concentration $C_{L}$ :

$$
t\left(C_{L}\right)=\frac{1}{k} \cdot \ln \left(\frac{C_{0}-C_{\infty}}{C_{L}-C_{\infty}}\right)
$$

Steady-state level of concentration $\left(C_{s}\right)$. This is the residual concentration of the drug. The value is chosen by assuming a neighborhood of convergence $\delta$ relative to the initial concentration:

$$
C_{s}(\delta)=C_{\infty}+\delta .\left|C_{0}-C_{\infty}\right|
$$

Settling time $\left(\boldsymbol{t}_{\boldsymbol{s}}\right)$. Time to reach the steady-state level of concentration $\boldsymbol{C}_{\boldsymbol{s}}$. It is obtained from formula (2), taking into account that $C_{L}=C_{S}$ :

$$
t_{s}\left(C_{s}\right)=\frac{1}{k} \cdot \ln \left(\frac{1}{\delta}\right)=t_{s}(\delta)
$$

Half-time for elimination $t_{1 / 2^{*}}$ The time required to eliminate one-half of the quantity of drug:

$$
t_{1 / 2}(\delta)=\frac{1}{k} \cdot \ln \left(\frac{2}{1+\delta}\right)
$$

Table 1 lists practical values for calculating the settling time $\boldsymbol{t}_{\boldsymbol{s}}$ and half-time $\boldsymbol{t}_{1 / 2}$ as a function of the absorption constant $\boldsymbol{k}$ for several commonly used values of $\boldsymbol{\delta}$.

Table 1. Dependence between $\boldsymbol{t}_{s}, \boldsymbol{t}_{1 / 2}$ and the rate constant $\boldsymbol{k}$

\begin{tabular}{|c|c|c|c|c|}
\hline $\boldsymbol{\delta}$ & 0,1 & 0,05 & 0,02 & 0,01 \\
\hline $\mathbf{t}_{\mathbf{s}}$ & $2,3 / \mathrm{k}$ & $3 / \mathrm{k}$ & $3,9 / \mathrm{k}$ & $4,6 / \mathrm{k}$ \\
\hline $\mathbf{t}_{1 / 2}$ & $0,598 / \mathrm{k}$ & $0,644 / \mathrm{k}$ & $0,673 / \mathrm{k}$ & $0,683 / \mathrm{k}$ \\
\hline
\end{tabular}

Area under curve - AUC for the interval $\left[0, t_{s}\right]$ is criteria for bioavailability:

$$
A U C=\int_{0}^{t_{S}}\left(\left[C(t)-C_{S}(\delta)\right]\right) d t=\int_{0}^{t_{S}}\left\{C(t)-\left[C_{\infty}+\delta\left(C_{0}-C_{\infty}\right)\right]\right\} d t
$$

Mean Residence Time (MRT). Used to determine the mean residence time of the drug in the animal's body:

IRTIIE Vol. 5, No. 4, 2017 ISSN 1314-8788 (print), ISSN 1314-8796 (online), doi: 10.15547/artte.2017.04.004 


\section{ARTIIIE}

$$
M R T=\frac{\int_{0}^{t_{S}} t \cdot C(t) d t}{\int_{0}^{t_{s}} C(t) d t}
$$

Process Energy E. The defined process energy $y(t)$ is:

$$
E=\int_{0}^{t_{S}}|y(t)|^{2} d t
$$

Process power $\mathbf{P}$. This indicator averages energy $\mathbf{E}$ over a certain period:

$$
P(\delta)=\frac{E}{t_{S}}=\frac{k \cdot E}{\ln (1 / \delta)}
$$

The listed parameters will be used to evaluate and compare the pharmacokinetic curves of the drugs. A statistically significant difference between the medications of the two manufacturers will be searched [3].

\section{RESULTS}

\subsection{Pharmacokinetic parameters}

The pharmacokinetic curves of the two forms of tilmicosin are presented in Figure 2. Statistical data for drug D1 are in Table 2 and for drug D2 - in Table 3. Visually, the differences in kinetic curves of the two drugs are negligible. This determines the need to introduce process identification and compare their dynamic parameters to look for statistically significant differences.

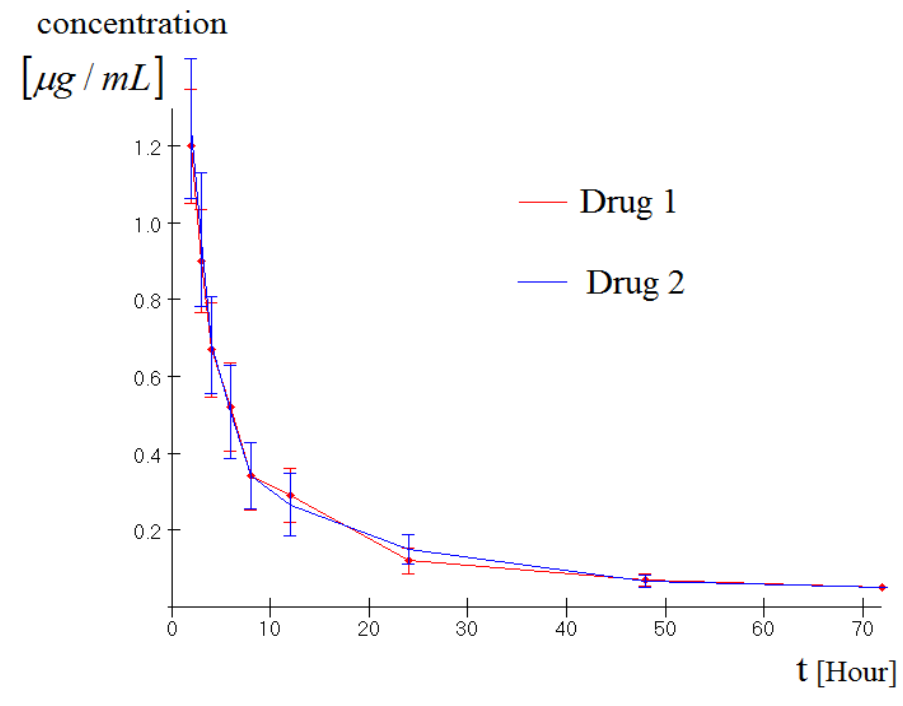

Figure 2. Kinetics of mean tilmicosin concentrations

IRITIE Vol. 5, No. 4, 2017 ISSN 1314-8788 (print), ISSN 1314-8796 (online), doi: 10.15547/artte.2017.04.004 
Table 2. Statistical parameters for drug D1

\begin{tabular}{|c|c|c|c|c|c|c|c|c|c|}
\hline Time, $\mathbf{h}$ & 2 & 3 & 4 & 6 & 8 & 12 & 24 & 48 & 72 \\
\hline $\begin{array}{c}\text { Average concentration C } \\
\mathbf{\mu g} / \mathbf{m l}\end{array}$ & 1,202 & 0,897 & 0,674 & 0,523 & 0,335 & 0,290 & 0,123 & 0,065 & 0,050 \\
\hline Standard deviation SD & 0,157 & 0,142 & 0,130 & 0,122 & 0,091 & 0,075 & 0,036 & 0,015 & 0,000 \\
\hline Skewness & $-0,515$ & 0,316 & $-0,224$ & $-0,208$ & $-0,042$ & $-0,062$ & 0,238 & 0,969 & - \\
\hline Kurtosis & $-0,579$ & $-1,124$ & $-1,028$ & $-1,002$ & $-1,379$ & $-1,176$ & $-0,795$ & 0,027 & - \\
\hline
\end{tabular}

Table 3. Statistical parameters for drug D2

\begin{tabular}{|c|c|c|c|c|c|c|c|c|c|}
\hline Time, $\mathbf{h}$ & 2 & 3 & 4 & 6 & 8 & 12 & 24 & 48 & 72 \\
\hline $\begin{array}{c}\text { Average concentration C } \\
\mathbf{\mu g} / \mathbf{m l}\end{array}$ & 1,245 & 0,955 & 0,682 & 0,507 & 0,340 & 0,266 & 0,125 & 0,065 & 0,050 \\
\hline Standard deviation SD & 0,182 & 0,175 & 0,125 & 0,122 & 0,087 & 0,082 & 0,039 & 0,016 & 0,000 \\
\hline Skewness & 0,040 & 0,115 & $-0,438$ & $-0,366$ & $-0,201$ & $-0,184$ & 0,136 & 0,572 & - \\
\hline Kurtosis & $-1,537$ & $-1,413$ & $-0,666$ & $-1,353$ & $-1,316$ & $-1,613$ & $-1,107$ & $-1,287$ & - \\
\hline
\end{tabular}

\subsection{Identification of a mathematical model}

To identify the model, a neighborhood $\delta=0.05$ is chosen. In order to increase the reliability of the model, corrective parameter $\boldsymbol{\beta}$ is introduced into the exponential equation (1):

$$
y(t)=\left(C_{0}-C_{\infty}\right) \cdot e^{-k \cdot(t+\beta)}+C_{\infty}
$$

Identification for each animal was performed with the Korelia-Ident program $[7,8]$. The data are in Table 4. The identification vector has been calculated, with a quadratic error minimization being selected for the optimization criterion. For each model, the coefficient of determination $\boldsymbol{R}^{2}$, Akaike information criterion (AIC) and corrected Akaike information criterion (AICC) was also calculated. The last two are used as an estimator of the relative quality of the models.

Table 4. Identified parameters for both drugs

\begin{tabular}{|c|c|c|c|c|c|c|c|c|}
\hline \multicolumn{4}{|c|}{ D1 } & \multirow[b]{2}{*}{ Pig } & \multicolumn{4}{|c|}{ D2 } \\
\hline $\mathrm{C}_{0}, \mu \mathrm{g} / \mathrm{ml}$ & $\begin{array}{c}C_{\infty} \\
\mu \mathrm{g} / \mathrm{ml}\end{array}$ & $\beta, h$ & $k, 1 / h$ & & $\mathrm{C}_{0}, \mu \mathrm{g} / \mathrm{ml}$ & $\begin{array}{c}\mathrm{C}_{\infty} \\
\mu \mathrm{g} / \mathrm{ml}\end{array}$ & $\beta, h$ & $k, 1 / h$ \\
\hline 1,813 & 0,092 & $-1,515$ & 0,266 & 1 & 2,008 & 0,120 & $-1,657$ & 0,206 \\
\hline 1,753 & 0,092 & $-1,757$ & 0,344 & 2 & 2,109 & 0,103 & 0,402 & 0,261 \\
\hline 1,866 & 0,092 & $-1,394$ & 0,239 & 3 & 1,932 & 0,085 & 0,288 & 0,278 \\
\hline 1,863 & 0,092 & $-1,454$ & 0,180 & 4 & 2,083 & 0,094 & 1,708 & 0,274 \\
\hline 1,690 & 0,060 & $-1,928$ & 0,286 & 5 & 2,215 & 0,124 & 0,266 & 0,250 \\
\hline 1,892 & 0,092 & $-1,090$ & 0,196 & 6 & 2,180 & 0,112 & 0,502 & 0,258 \\
\hline 1,885 & 0,092 & $-1,879$ & 0,209 & 7 & 1,942 & 0,083 & 1,089 & 0,304 \\
\hline 1,817 & 0,092 & $-1,879$ & 0,216 & 8 & 1,837 & 0,077 & 1,501 & 0,315 \\
\hline 1,803 & 0,119 & $-2,029$ & 0,258 & 9 & 1,911 & 0,071 & 1,324 & 0,354 \\
\hline 1,849 & 0,092 & $-1,636$ & 0,292 & 10 & 2,316 & 0,130 & 0,294 & 0,250 \\
\hline 1,823 & 0,092 & $-1,656$ & 0,249 & average & 2,058 & 0,098 & 0,819 & 0,283 \\
\hline 0,063 & 0,014 & 0,293 & 0,050 & SD & 0,162 & 0,021 & 0,583 & 0,035 \\
\hline$-1,095$ & $-0,627$ & 0,639 & 0,482 & skewness & 0,198 & 0,373 & 0,484 & 1,159 \\
\hline 0,896 & 4,689 & $-0,211$ & $-0,256$ & kurtosis & $-1,223$ & $-1,248$ & $-1,795$ & 0,738 \\
\hline
\end{tabular}

IRTIIE Vol. 5, No. 4, 2017 ISSN 1314-8788 (print), ISSN 1314-8796 (online), doi: 10.15547/artte.2017.04.004 


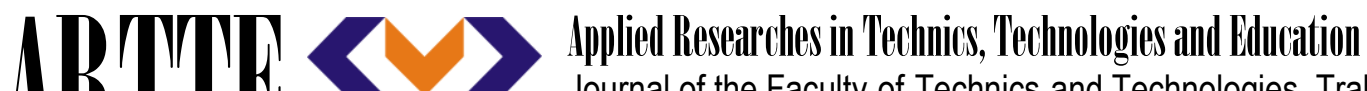 Journal of the Faculty of Technics and Technologies, Trakia University https://sites.google.com/a/trakia-uni.bg/artte/}

The identification of the two kinetic curves based on average values determined the following equations:

Concentration model of D1:

$$
C 1(t)=1.731 . e^{-0.240(t-1.656)}+0.092
$$

Coefficient of determination $\boldsymbol{R}^{2}=0.9822 ; \mathrm{AIC}=-45.92 ; \mathrm{AICC}=-36.67$

Concentration of D2:

$$
C 2(t)=1.960 \cdot e^{-0.279(t+0.819)}+0.098
$$

Coefficient of determination $\boldsymbol{R}^{2}=0.9851 ; \mathrm{AIC}=-46.51 ; \mathrm{AICc}=-37.36$

The graphs of the two models are in Figure 3.

$$
\text { concentration }
$$

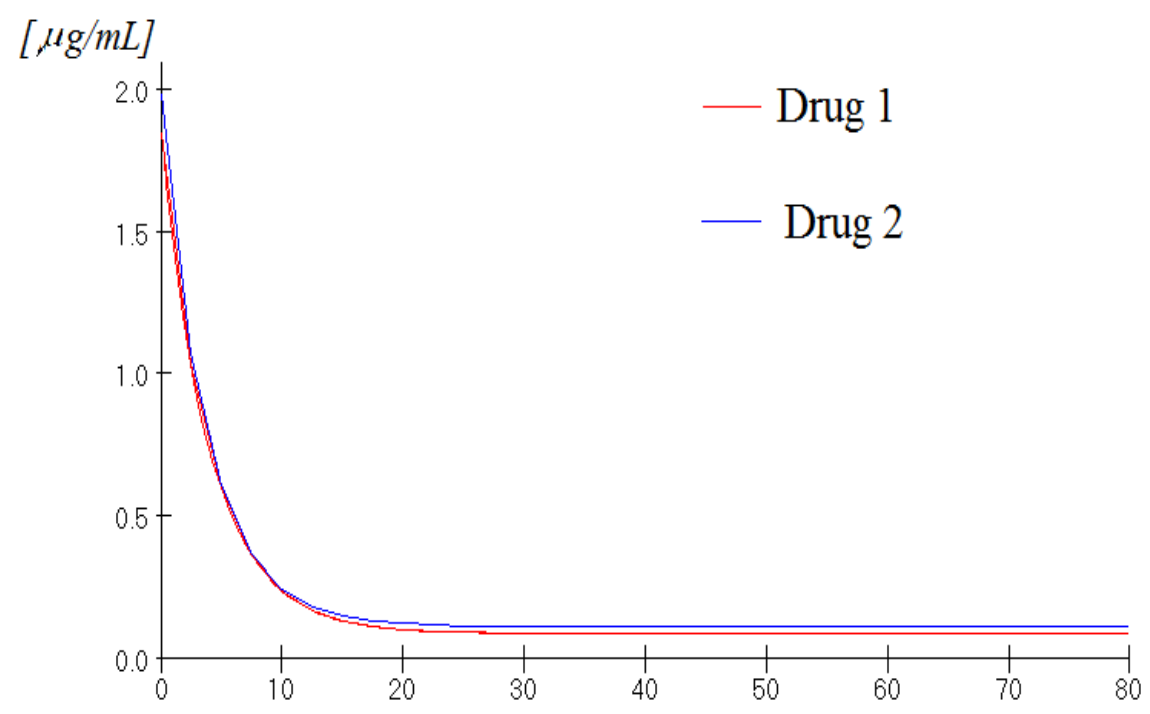

Figure 3. Graphics of the mathematical models

\subsection{Dynamic parameters of drugs}

For each pig, the dynamic parameters of the process were calculated. The data for D1 are in Table 5 and for D2 in Table 6. 
Table 5. Dynamic parameters of drug D1

\begin{tabular}{|c|c|c|c|c|c|c|c|c|}
\hline Pig & $\begin{array}{c}C_{s}, \\
\mu g / m l\end{array}$ & $t_{1 / 2}, h$ & $\mathbf{T}_{\mathrm{s}}, \mathbf{h}$ & $\mathrm{S}_{\mathrm{r}}, \mu \mathrm{g} \cdot \mathrm{h} / \mathrm{ml}$ & $\begin{array}{c}\text { AUC, } \\
\mu \mathrm{g} . \mathrm{h} / \mathrm{ml}\end{array}$ & $\begin{array}{c}\text { MRT, } \\
\mu \mathrm{g} \cdot \mathrm{h}^{2} / \mathrm{ml}\end{array}$ & $\mathrm{E}, \mu \mathrm{g}^{2} \cdot \mathrm{h} / \mathrm{ml}^{2}$ & $P, \mu g^{2} / \mathrm{ml}^{2}$ \\
\hline 1 & 0,178 & 2,421 & 11,254 & 18,399 & 5,835 & 4,091 & 0,847 & 0,075 \\
\hline 2 & 0,175 & 1,874 & 8,714 & 13,746 & 4,359 & 3,177 & 0,626 & 0,072 \\
\hline 3 & 0,181 & 2,694 & 12,529 & 21,116 & 6,696 & 4,542 & 0,981 & 0,078 \\
\hline 4 & 0,180 & 3,574 & 16,615 & 27,959 & 8,866 & 6,023 & 1,292 & 0,078 \\
\hline 5 & 0,142 & 2,256 & 10,489 & 16,248 & 5,152 & 3,715 & 0,559 & 0,053 \\
\hline 6 & 0,182 & 3,279 & 15,253 & 26,080 & 8,271 & 5,523 & 1,217 & 0,080 \\
\hline 7 & 0,182 & 3,085 & 14,341 & 24,419 & 7,744 & 5,197 & 1,138 & 0,079 \\
\hline 8 & 0,179 & 2,987 & 13,888 & 22,754 & 7,216 & 5,048 & 1,048 & 0,076 \\
\hline 9 & 0,203 & 2,501 & 11,629 & 18,610 & 5,902 & 4,336 & 1,034 & 0,089 \\
\hline 10 & 0,180 & 2,206 & 10,256 & 17,115 & 5,428 & 3,722 & 0,793 & 0,077 \\
\hline average & 0,178 & 2,688 & 12,497 & 20,645 & 6,547 & 4,538 & 0,954 & 0,076 \\
\hline SD & 0,015 & 0,534 & 2,485 & 4,601 & 1,459 & 0,901 & 0,244 & 0,009 \\
\hline skewness & $-1,433$ & 0,215 & 0,215 & 0,197 & 0,197 & 0,179 & $-0,354$ & $-1,686$ \\
\hline kurtosis & 5,232 & $-0,843$ & $-0,846$ & $-1,030$ & $-1,030$ & $-0,881$ & $-0,886$ & 4,980 \\
\hline
\end{tabular}

Table 5. Dynamic parameters of drug D2

\begin{tabular}{|c|c|c|c|c|c|c|c|c|}
\hline Pig & $\begin{array}{c}C_{s} \\
\mu \mathrm{g} / \mathrm{ml}\end{array}$ & $t_{1 / 2,}, h$ & $T_{s}, h$ & $S_{r}, \mu g \cdot h / m l$ & $\begin{array}{c}\text { AUC, } \\
\mu \mathrm{g} . \mathrm{h} / \mathrm{ml}\end{array}$ & $\begin{array}{c}\text { MRT, } \\
\mu \mathrm{g} \cdot \mathrm{h}^{2} / \mathrm{ml}\end{array}$ & $E, \mu g^{2} \cdot h / m l^{2}$ & $P, \mu g^{2} / \mathrm{ml}^{2}$ \\
\hline 1 & 0,214 & 3,129 & 14,550 & 26,105 & 8,279 & 5,368 & 1,492 & 0,103 \\
\hline 2 & 0,207 & 2,467 & 11,275 & 21,665 & 6,871 & 4,153 & 1,154 & 0,102 \\
\hline 3 & 0,178 & 2,319 & 10,784 & 18,916 & 5,999 & 3,876 & 0,845 & 0,078 \\
\hline 4 & 0,194 & 2,349 & 10,925 & 20,638 & 6,545 & 3,933 & 1,010 & 0,092 \\
\hline 5 & 0,229 & 2,576 & 11,978 & 23,799 & 7,547 & 4,392 & 1,430 & 0,119 \\
\hline 6 & 0,216 & 2,501 & 11,629 & 22,841 & 7,243 & 4,231 & 1,272 & 0,109 \\
\hline 7 & 0,176 & 2,122 & 9,867 & 17,428 & 5,527 & 3,537 & 0,764 & 0,077 \\
\hline 8 & 0,165 & 2,046 & 9,513 & 15,904 & 5,044 & 3,405 & 0,652 & 0,069 \\
\hline 9 & 0,163 & 1,819 & 8,458 & 14,784 & 4,688 & 3,004 & 0,589 & 0,070 \\
\hline 10 & 0,239 & 2,576 & 11,978 & 24,874 & 7,888 & 4,392 & 1,565 & 0,131 \\
\hline average & 0,198 & 2,309 & 11,096 & 20,695 & 6,563 & 3,880 & 1,077 & 0,095 \\
\hline SD & 0,027 & 0,262 & 1,663 & 3,854 & 1,222 & 0,479 & 0,358 & 0,021 \\
\hline skewness & 0,069 & $-0,820$ & 0,559 & $-0,207$ & $-0,207$ & $-0,716$ & 0,007 & 0,257 \\
\hline kurtosis & $-1,424$ & $-0,294$ & 1,379 & $-1,223$ & $-1,223$ & $-0,437$ & $-1,614$ & $-1,118$ \\
\hline
\end{tabular}

\section{DISCUSSION}

In Table 7 are the calculated significance levels for the concentration measured during the experiment. Comparison of the plasma concentrations of the two antibiotics did not indicate a statistically significant difference in the pharmacokinetic curves. The process of elimination proceeds uniformly.

Table 7. p-level of the plasma concentration by hours

\begin{tabular}{|c|c|c|c|c|c|c|c|c|c|}
\hline Time, $\mathbf{h}$ & 2 & 3 & 4 & 6 & 8 & 12 & 24 & 48 & 72 \\
\hline p-level & 0,587 & 0,426 & 0,890 & 0,770 & 0,905 & 0,504 & 0,930 & 1,000 & 1,000 \\
\hline
\end{tabular}




\section{ARTTIE $Y$}

Ipplied Resseirlores in Technics, Technologies and Educration

Journal of the Faculty of Technics and Technologies, Trakia University https://sites.google.com/a/trakia-uni.bg/artte/

Table 8. Identified parameters: $p$-level

\begin{tabular}{|c|c|c|c|c|}
\hline Parameter & $\mathbf{C}_{0}$ & $\mathbf{C}_{\infty}$ & $\boldsymbol{\beta}$ & $\mathbf{k}$ \\
\hline p-level & $\mathbf{0 , 0 0 0 5 3}$ & 0,47851 & $\mathbf{0 , 0 0 0 0 0}$ & 0,10948 \\
\hline
\end{tabular}

The evaluation of the parameters of the mathematical model of the two drugs showed a statistically significant difference for the initial value $\boldsymbol{C}_{0}$ and the correction parameter $\boldsymbol{\beta}$ (Table 8). These two parameters reflect the concentration of the drug at the initial time. The difference can be explained by the operational differences of the laboratory assistants, as well as by slight deviations in the timing of sampling [9].

Table 9. Level of significance for dynamics parameters

\begin{tabular}{|c|c|c|c|c|c|c|c|c|}
\hline Parameter & $\mathbf{C}_{\mathbf{s}}$ & $\mathbf{t}_{1 / 2}$ & $\mathbf{t}_{\mathbf{s}}$ & $\mathbf{S}_{\mathbf{r}}$ & AUC & MRT & $\mathbf{E}$ & $\mathbf{P}$ \\
\hline p-level & 0,05983 & 0,07096 & 0,15568 & 0,97895 & 0,97895 & 0,16539 & 0,37818 & 0,01706 \\
\hline
\end{tabular}

A statistically significant difference is established only for the power of the processes.

The final conclusion that can be drawn from the conducted study is that there is no difference in the pharmacokinetic of the two forms of tilmicosin.

\section{CONCLUSION}

In the present study, two production forms of the antibiotic tilmicosin have been compared. A new approach to assessing the pharmacokinetic curves is applied - identification of a mathematical model. With his help, the dynamic parameters of the two drugs were calculated. A statistically significant difference was found only in the parameter "power" of the pharmacokinetic curve. The final conclusion is that the two forms of tilmicosin have the same effect on the experimental animals.

\section{ACKNOWLEDGEMENTS}

This study was supported by Grant 3ФTT/30.04.2015 "Identification and Simulation of Second-order Dynamic Models" from the Faculty of Technics and Technologies, Trakia University - Yambol, Bulgaria.

The authors express their deep gratitude to Prof. D. Dimitrova, PhD, University of Forestry, Sofia for the data provided without which this work would not have been possible.

\section{REFERENCES}

[1] Dimitrova D. (2011). Pharmacokinetics of tilmicosin after oral application of Pulmotil G 200 - premix in pigs. Agricultural Science and Technology. vol.3 (4). pp.318-322.

[2] Dimitrova D. (2013). Pharmacokinetics of some antimicrobial chemotherapeutics in veterinary medicine. "Litera print" AD - Stara Zagora, 2013. ISBN 978-954-487-114-7.

[3] Lessard Charles S. (2006). Signal Processing of Random Physiological Signals. Texas A\&M University, College Station, USA. 2006 Morgan \& Claypool Publishers.

[4] Yankov K. (1998). Evaluation of Some Dynamics Characteristics of Transient Processes. 12-th Int.Conf.SAER'98. , sept.19-20, 1998, Varna, Bulgaria. pp. 113-117.

[5] Yankov K. (1998). Software Utilities for Investigation of Regulating Systems, Proc. Ninth Nat. Conf. "Modern Tendencies in the Development of Fundamental and Applied Sciences". June, 5-6, 1998, Stara Zagora, Bulgaria, pp.401-408. 


\section{IRTTE

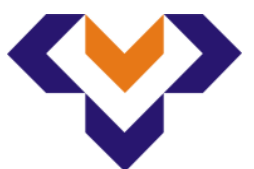 \\ Ipplied Resseirlohes in Technics, Technologies and Eductition Journal of the Faculty of Technics and Technologies, Trakia University https://sites.google.com/a/trakia-uni.bg/artte/}

[6] Yankov K. (2011). Evaluation of Characteristic Parameters of Dynamic Models. Proc. Int. Conference on Information Technologies (InfoTech-2011). St. Constantine and Elena resort, Bulgaria,sept.15-17, 2011, pp.225-234. ISSN 1314-1023.

[7] Yankov K. (2010). Preprocessing of Experimental Data in Korelia Software. Trakia Journal of Sciences, Vol. 8, Suppl. 3, pp. 41-48, 2010. ISSN 1313-7069.

[8] Yankov K. (2015). Assessment of Processes Using Identification Models. Applied Researches in Technics, Technologies and Education, 2015, ARTTE Vol. 3, No. 1, 2015, ISSN 1314-8788 (print), ISSN 1314-8796 (online), pp. 52-60.

[9] Yankov K., D. Ilieva. (2015). User Interface for Analysis of Experimental Data. Trakia Journal of Sciences, Vol. 13, Suppl. 1, pp 420-425, 2015 ISSN 1313-7069 (print), ISSN 1313-3551 (online). 